\title{
Comparison of ultrasonography and Intravenous urography in predicting the outcome of Extracorporeal Shockwave lithotripsy in nephrolithiasis
}

\author{
Lynser $D^{1}$, Sinam $S^{2}$, Singh $\mathrm{LS}^{3}$ \\ ${ }^{1}$ Dr Donboklang Lynser, MD, Radiologist, Ganesh Das Hospital, Shillong, ${ }^{2}$ Dr Sekharjit Singh Sinam, MCh Professor of \\ Urology, Regional Institute of Medical Sciences, Imphal, Manipur. ${ }^{3}$ Dr L. Surendra Singh, MD, Professor of \\ Radiodiagnosis, Regional Institute of Medical Sciences, Imphal, Manipur, India
}

Address for Correspondence: Dr Donboklang Lynser, MD, Radiologist, Ganesh Das Hospital, Shillong, E-mail ID: bokdlynser@yahoo.co.in,

\begin{abstract}
Introduction: ultrasound has a well established role in evaluating the kidney. Calculus is readily picked up on ultrasound. Normal sonographic features with doppler detection of ureteric jets indicate presence of normal renal function. Using these advantages we undertook this present study to determine whether ultrasound (USG) can replace intravenous urography (IVU) in the pre-operative evaluation of extracorporeal shockwave lithotripsy (ESWL) patients. Methods and Material: This study was a prospective observational study conducted in the Department of Radiodiagnosis, Regional Institute of Medical Sciences (RIMS), Imphal, during a period of 2 years. 50 patients with confirmed renal stones referred for ESWL treatment in the Department of Urology, RIMS, Hospital, Imphal were included. USG and IVU were independently interpreted. Cases were grouped as excellent, good, borderline or poor cases. Sensitivity, specificity, positive predictive value (PPV) and negative predictive value (NPV) of USG and IVU are compared. Results: The sensitivity and specificity of ultrasound in predicting the outcome after ESWL for solitary renal calculus is $95.8 \%$ and $50 \%$ respectively with a PPV and NPV of $97.8 \%$ and $33.33 \%$ respectively and the sensitivity and specificity of IVU in predicting the outcome after ESWL are $97.9 \%$ and 50\% respectively with a PPV and NPV of $97.8 \%$ and $50 \%$ respectively. Conclusions: USG can be the alternative radiological examination in the pre-operative evaluation of ESWL patients as the USG and IVU have comparable predictive values.
\end{abstract}

Key words: Ultrasound; Intravenous Urography, Renal calculus; Lithotripsy, Hydronephrosis.

\section{Introduction}

Ultrasonography has a well established role in evaluating the kidney. It can determine solid or cystic lesions, stone in the collecting system, tumors, renal or peri-renal collections and chronic renal diseases. Each human adult Kidney weighs about $150 \mathrm{gm}$. As the ureter enters the kidney at the pelvis, it divides into 2 to 3 major and each into 3 to 4 minor calyces. The cortex measures approximately $1.2-1.5 \mathrm{~cm}$ in thickness. The medulla consists of renal pyramids, the apices of which are called papillae, each related to a calyx.

The renal medullary pyramids are hypoehoic relative to

Manuscript received: $10^{\text {th }}$ Oct 2015

Reviewed: $20^{\text {th }}$ Oct 2015

Author Corrected: $4^{\text {th }}$ Nov 2015

Accepted for Publication: $12^{\text {th }}$ Nov 2015 renal cortex and can be identified in most normal adult. The normal renal cortex has classically been described as being less echogenic than adjacent liver and spleen [1].

Hydronephrosis is defined as an aseptic dilatation of the kidney due to partial or complete obstruction to the outflow of urine [2].

A four grade classification is used for hydronephrosis based on excretory urography or ultrasound (USG). Grade $I$ is the most minimal dilatation appreciable, characterized by slight blunting of the caliceal fornices. Successful abdominal compression during excretory urography in a nonobstructed patient often produces a picture of grade I hydronephrosis. Similarly, a well 
hydrated patient often produces a picture of grade I hydronephrosis on ultrasound. Grade II has obvious blunting of the caliceal fornices and enlargement of the calices, but the intruding shadows of the papillae, although flattened, are still easily seen. Grade III is rounding of the calices with obliteration of the papillae. Grade IV defines extreme caliceal ballooning. Grade II, III, IV correspond to mild, moderate and severe grades of hydronephrosis respectively [3].

For lithotripsy to be successful a stone must first be imaged accurately then fragmented completely and finally the fragments must be passed. Imaging of non opaque renal stone can be achieved either with USG or radiography as a negative shadow after intravenous urography (IVU) or retrograde pyelography. The potential for breaking the stone into fragments will vary depending on the lithotripter, the density of stone and the number of treatment sessions given.

Lithotripsy should not ordinarily be attempted if there is obstruction distal to the stone. Such obstruction is seen when stones are associated with uretero pelvic junction (UPJ) obstruction. The overall size of the stone is a limiting factor for lithotripsy as monotherapy. The upper limit of the size of the stone which can be safely and reliably treated is $2.5 \mathrm{~cm}$. Above this size some form of adjuvant must be incorporated into the overall treatment plan [4].

The advantages of USG as a non-invasive, less expensive and radiation hazard free procedure have made us question the investigation of choice in the Preoperative evaluation for extracorporeal shock wave lithotripsy (ESWL) patients.

Aims and objectives: this prospective study was undertaken to determine whether sonography could supplant IVU in the evaluation of prospective ESWL patients.

\section{Subjects and Methods}

This study was a prospective study conducted in the Department of Radiodiagnosis, Regional Institute of Medical Sciences (RIMS), Imphal, during a period of 2 years from September 2003 to October 2005. Study was conducted only after the protocol was approved by the institute board. Informed consent was taken from all patients. 50 patients with comfirmed renal stones (confirmed by USG or X ray KUB) referred for ESWL treatment in the Department of Urology, RIMS,
Hospital, Imphal were taken up as cases. Adult patients with solitary stone of sizes less than $2.5 \mathrm{~cm}$ were selected. The patients were preoperatively evaluated by both USG and IVU independently in the Department of Radiodiagnosis RIMS, Hospital, Imphal. In every case USG and IVU were performed independently and interpreted without knowledge of the other. Prior to USG or IVU a plain abdominal x-ray kidney ureter bladder region (KUB) was taken for each of these patients. ESWL was done using Dornier compact $\mathrm{S}$ shockwave lithotripter machine with dual monitoring (by fluoroscopy and ultrasound). Ultrasound examination was done with Curvilinear probe $3-5 \mathrm{Mhz}$ using Siemens Sonoline versa plus ultrasound system.

In case of ultrasound examination only those having ureteric jets on colour doppler were selected.

Cases having ureteric dilatation distal to the calculus and those having increased parenchymal echogenicity compared to the liver and spleen were excluded from the study.

Cases having abnormal serum urea and creatinine values were also excluded from the study.

USG: was done on a lateral decubitus position. The following parameters were recorded.

1. Calyceal Dilatation: No dilatation, mild, moderate and severe

2. Parenchymal echogenicity: compared with liver and spleen (a) normal (b) increased. Thickness of the Parenchyma was measured from the edge of the calyx to the renal outline.

3. Location of Stone: upper, middle, lower calyx, pelvis and uretero-pelvic junction (UPJ).

4. Ureter: A search for ureteric dilatation or any obstruction distal the renal calculus was made.

5. Specific: Renal mass if present to be graded as cystic, solid or complex.

\section{Size of the kidney was measured.}

IVU: Intravenous urography was performed after a plain film of the abdomen and pelvis was obtained. Iodinated contrast was administered intravenously at the dose of $300 \mathrm{mg} / \mathrm{Kg}$ in a bolus, precautions taken for those patients with history of allergy. Radiographs were taken at 5 minute post injection for kidney and 10 minutes or 15 minutes for ureter. Further films were taken on the basis of the radiographic findings. Following parameters were recorded for IVU,

1. Calyceal Dilatation: No dilatation, mild, moderate and severe. 
2. Renal Parenhymal Thickness: Renal parenchymal thickness was assessed by measuring the distance between the edge of the calyx and outer surface of the nephrogram.

3. Position of Stone: upper, middle, lower calyx, pelvis and UPJ.

\section{Renal sizes were measured.}

The patients were group into Excellent, good, borderline and poor groups based on certain diagnostic criteria's (like dilatation, stone location in the kidney, parenchymal thickness, renal sizes, cortical echogenicity and any other associated abnormality). Kidneys having normal renal size, parenchymal thickness and echogenicity therefore ruling out the possible sonographic features associated with nonfunctioning kidneys were considered to have normal renal function in consensus with Behan et al [5]. Good parenchymal thickness is related with good renal function while increased cortical echogenicity and thinning are associated with chronic parenchymal disease which was corroborated by Beland et [6] in 2010 who demonstrated a strong relation between cortical thickness and renal function and Siddappa et al who in 2013 showed statistically significant positive correlations between serum creatinine and renal echogenicity grading [7]. Based on these parameters, predicted outcome from USG and IVU were independently grouped as excellent, good, borderline and poor following our devised method in Table 1.

Table 1: showing the Grouping of patients for extrocorporeal shockwave lithotripsy (ESWL) on solitary renal calculus according to ultrasound (USG) and intravenous urography(IVU)

\begin{tabular}{|l|l|l|}
\hline Groups & USG & IVU \\
\hline Excellent & $\begin{array}{l}\text { Non dilated collecting system, calculus in the pelvis or } \\
\text { non dependent calyces having normal parenchymal } \\
\text { thickness, renal size and echogenity }\end{array}$ & $\begin{array}{l}\text { Non dilated collecting system, } \\
\text { calculus in the pelvis or non } \\
\text { dependent calyces }\end{array}$ \\
\hline Good & $\begin{array}{l}\text { Mild/ moderate dilated collecting system or lower } \\
\text { calyceal calculus without dilatation having normal } \\
\text { parenchymal thickness, renal size and echogenicity }\end{array}$ & $\begin{array}{l}\text { Mild/ moderate dilated collecting } \\
\text { system or lower calyceal calculus } \\
\text { without dilatation }\end{array}$ \\
\hline Borderline & $\begin{array}{l}\text { Gross dilated pelvicalcyceal system or lower calyceal } \\
\text { calculus with any dilatation having reasonable amount of } \\
\text { parenchymal thickness with normal echogenicity }\end{array}$ & $\begin{array}{l}\text { Gross dilated pelvicalcyceal system } \\
\text { or lower calyceal calculus with any } \\
\text { dilatation }\end{array}$ \\
\hline Poor & $\begin{array}{l}\text { Infundibular stenosis, calcyceal cyst or diverticuli with } \\
\text { thinned out parenchyma having normal echogenicity }\end{array}$ & $\begin{array}{l}\text { Infundibular stenosis, calcyceal cyst } \\
\text { or diverticuli with poor functioning } \\
\text { on IVU }\end{array}$ \\
\hline
\end{tabular}

Successful cases is defined as those having no calculus on a repeat plain film KUB with ultrasound, and unsuccessful cases are those having significant residual fragments for more than 3 months after lithotripsy.

\section{Results}

Table 2: Showing the distribution of renal calculus according to age groups and sex

\begin{tabular}{|l|l|l|l|l|}
\hline Age Group & No of cases & Percentage & M & F \\
\hline $10-20$ & 3 & $6 \%$ & 1 & 2 \\
\hline $21-30$ & 11 & $22 \%$ & 7 & 4 \\
\hline $31-40$ & 16 & $32 \%$ & 9 & 7 \\
\hline $41-50$ & 9 & $9 \%$ & 7 & 2 \\
\hline $51-60$ & 8 & $8 \%$ & 6 & 2 \\
\hline $61-70$ & 3 & $3 \%$ & 3 & 0 \\
\hline Total & $\mathbf{5 0}$ & $\mathbf{1 0 0 \%}$ & $\mathbf{3 3}$ & $\mathbf{1 7}$ \\
\hline
\end{tabular}

The age ranges from 18 to 70 years with a mean of 38.90 years. Male constitute the larger group with a ratio of $\mathrm{M}: \mathrm{F}=1.94: 1$. Maximum distribution is in the age group 21-40 (54\%). There were $6(12 \%)$ lucent and 44 radio-opaque $(88 \%)$ solitary stones. Calculi $\leq 10 \mathrm{~mm}$ constitute $52 \%$ of the total number of solitary renal calculus. 
Table 3: Showing comparison of USG and IVU in the diagnosis of hydronephrosis in 50 patients (total 100 renal units)

\begin{tabular}{|l|l|l|}
\hline Ultrasound Examination & IVU Diagnosis & 4 \\
\hline Hydronephrosis present (34) & 30 & 65 \\
\hline Hydronephrosis absent (66) & 1 & \\
\hline
\end{tabular}

Considering the IVU as the gold standard in the diagnosis of hydronephrosis, we compared the USG with IVU in 100 renal units. We found out that the sensitivity and specificity of ultrasound in the diagnosis of hydronephrosis are $96.7 \%$ and $94.2 \%$ respectively.

Table 4: Showing the outcome of extracorporeal shockwave lithotripsy according to prediction by intravenous urography (IVU) and ultrasound (USG).

\begin{tabular}{|c|c|c|c|c|c|c|c|}
\hline & & \multicolumn{4}{|c|}{ Successful outcome } & \multirow{2}{*}{\multicolumn{2}{|c|}{$\begin{array}{l}\text { Unsuccessful } \\
\text { outcome }\end{array}$}} \\
\hline \multicolumn{2}{|l|}{ GROUPS } & \multicolumn{2}{|c|}{$\begin{array}{l}\text { Calculi needing 1- } \\
2 \text { sessions }\end{array}$} & \multicolumn{2}{|c|}{$\begin{array}{l}\text { Calculi needing } \\
\text { 3-4 sessions }\end{array}$} & & \\
\hline IVU & USG & IVU & USG & IVU & USG & IVU & USG \\
\hline $\begin{array}{l}\text { Excellent } \\
\mathrm{n}=17\end{array}$ & $\begin{array}{l}\text { Excellent } \\
\mathrm{n}=14\end{array}$ & $\begin{array}{l}100 \% \\
(\mathrm{n}=17)\end{array}$ & $\begin{array}{l}100 \% \\
(n=14)\end{array}$ & $0 \%$ & $0 \%$ & $0 \%$ & $0 \%$ \\
\hline $\begin{array}{l}\text { Good } \\
\mathrm{n}=31\end{array}$ & $\begin{array}{l}\text { Good } \\
n=33\end{array}$ & $\begin{array}{l}87.10 \% \\
(\mathrm{n}=27)\end{array}$ & $\begin{array}{l}84.8 \% \\
(\mathrm{n}=28)\end{array}$ & $\begin{array}{l}12.9 \% \\
(\mathrm{n}=4)\end{array}$ & $\begin{array}{l}12.1 \% \\
(\mathrm{n}=4)\end{array}$ & $0 \%$ & $\begin{array}{l}3.03 \% \\
(\mathrm{n}=1)\end{array}$ \\
\hline $\begin{array}{l}\text { Borderline } \\
n=2\end{array}$ & $\begin{array}{l}\text { Borderline } \\
\mathrm{n}=3\end{array}$ & $\begin{array}{l}50 \% \\
(n=1)\end{array}$ & $\begin{array}{l}66.7 \% \\
(\mathrm{n}=2)\end{array}$ & $0 \%$ & $0 \%$ & $\begin{array}{l}50 \% \\
(n=1)\end{array}$ & $\begin{array}{l}33.3 \% \\
(\mathrm{n}=1)\end{array}$ \\
\hline
\end{tabular}

In the excellent group all the calculi cleared in 1 or 2 sessions, however the good and borderline groups have cases clearing in 3 or more sessions along with 2 unsuccessful outcomes. There was no poor group included in our study possibly because lithotripsy was not advised due to unfavourable pre-ESWL radiological findings.

Table 5: Showing stone clearance post extracorporeal shockwave lithotripsy according to stone location in the kidney

\begin{tabular}{|c|c|c|c|c|c|}
\hline $\begin{array}{l}\text { Location of } \\
\text { calculus }\end{array}$ & $\begin{array}{l}\text { Cleared in } 1 \\
\text { session }\end{array}$ & $\begin{array}{l}\text { Cleared in } 2 \\
\text { session }\end{array}$ & $\begin{array}{l}\text { Cleared in } 3 \\
\text { session }\end{array}$ & $\begin{array}{l}\text { Cleared in } 4 \\
\text { session }\end{array}$ & $\begin{array}{l}\text { Unsuccessful } \\
\text { outcome }\end{array}$ \\
\hline $\begin{array}{l}\text { Upper calyx } \\
(\mathrm{n}=7)\end{array}$ & $\begin{array}{l}57.14 \% \\
(n=4)\end{array}$ & $\begin{array}{l}28.57 \% \\
(n=2)\end{array}$ & $0 \%$ & $\begin{array}{l}14.29 \% \\
(\mathrm{n}=1)\end{array}$ & $0 \%$ \\
\hline $\begin{array}{l}\text { Middle calyx } \\
(n=12)\end{array}$ & $\begin{array}{l}66.67 \% \\
(n=8)\end{array}$ & $\begin{array}{l}25 \% \\
(\mathrm{n}=3)\end{array}$ & $0 \%$ & $\begin{array}{l}8.33 \% \\
(\mathrm{n}=1)\end{array}$ & $0 \%$ \\
\hline $\begin{array}{l}\text { Lower calyx } \\
(\mathrm{n}=4)\end{array}$ & $\begin{array}{l}50 \% \\
(\mathrm{n}=2)\end{array}$ & $0 \%$ & $\begin{array}{l}25 \% \\
(\mathrm{n}=1)\end{array}$ & $0 \%$ & $\begin{array}{l}25 \% \\
(\mathrm{n}=1)\end{array}$ \\
\hline $\begin{array}{l}\text { Pelvis } \\
(\mathrm{n}=19)\end{array}$ & $\begin{array}{l}68.42 \% \\
(\mathrm{n}=13)\end{array}$ & $\begin{array}{l}26.32 \% \\
(n=5)\end{array}$ & $0 \%$ & $0 \%$ & $\begin{array}{l}5.26 \% \\
(\mathrm{n}=1)\end{array}$ \\
\hline $\begin{array}{l}\text { UPJ } \\
(n=8)\end{array}$ & $\begin{array}{l}50 \% \\
(\mathrm{n}=4)\end{array}$ & $\begin{array}{l}37.5 \% \\
(\mathrm{n}=3)\end{array}$ & $0 \%$ & $\begin{array}{l}12.5 \% \\
(\mathrm{n}=1)\end{array}$ & $0 \%$ \\
\hline
\end{tabular}

Of the stone location in the kidney successful outcome after 1 to 4 sessions is seen in all upper, UPJ and middle calyceal calculi. Of the 4 lower calyceal calculi in our series, 1 required 3 ESWL sessions and the other resulted in unsuccessful outcome. Out of 19 pelvic calculi 1 resulted in unsuccessful outcome $(5.2 \%)$.

Table 6: showing number of extracorporeal shockwave (ESWL) sessions required according to stone sizes.

\begin{tabular}{|l|l|l|l|l|}
\hline $\begin{array}{l}\text { Stone sizes with successful } \\
\text { outcomes }\end{array}$ & $\begin{array}{l}\text { Number of cases } \\
\text { with successful } \\
\text { outcomes }\end{array}$ & $\begin{array}{l}\text { Total number of } \\
\text { sessions }\end{array}$ & $\begin{array}{l}\text { Range of } \\
\text { sessions }\end{array}$ & $\begin{array}{l}\text { Mean number of } \\
\text { sessions }\end{array}$ \\
\hline$\leq 10 \mathrm{~mm}$ & $\mathrm{n}=25$ & 31 & $1-2$ & 1.24 \\
\hline $11-20 \mathrm{~mm}$ & $\mathrm{n}=22$ & 37 & $1-4$ & 1.68 \\
\hline$\geq 21 \mathrm{~mm}$ to $<25 \mathrm{~mm}$ & $\mathrm{n}=1$ & 4 & 4 & 4 \\
\hline
\end{tabular}


In our series, the number of ESWL sessions required to achieve successful outcome is lesser for smaller stones. The largest stone in our series seen in the UPJ and requires 4 sessions of ESWL.

Table 7: showing comparison of USG and IVU in predicting the outcome after lithotripsy

\begin{tabular}{|l|l|l|l|l|}
\hline \multicolumn{2}{|l|}{} & \multicolumn{2}{|l|}{ Outcome as predicted by } \\
\hline \multirow{2}{*}{ Groupings } & Ultrasound & \multicolumn{2}{l|}{ Intravenous urography } \\
\cline { 2 - 5 } & Successful & Unsuccessful & Successful & Unsuccessful \\
\hline Excellent and Good & 46 & 1 & 47 & 1 \\
\hline $\begin{array}{l}\text { Borderline and } \\
\text { poor }\end{array}$ & 2 & 1 & 1 & 1 \\
\hline
\end{tabular}

In our series out of the 48 excellent and good cases in IVU, 47 resulted in successful outcome and the only 1 resulted in unsuccessful outcome. Of the borderline and poor case 1 resulted in successful and 1 in unsuccessful outcome. Therefore the sensitivity and specificity of IVU in predicting the outcome after ESWL for solitary renal calculus $<25 \mathrm{~mm}$ are $97.9 \%$ and $50 \%$ respectively with a positive and negative predictive value of $97.8 \%$ and $50 \%$ respectively. For the ultrasound, of the 47 excellent and good cases, 46 resulted in successful outcome and only 1 resulted in successful outcome. Of the borderline and poor case 2 resulted in successful outcome and 1 in in unsuccessful outcome. Therefore the sensitivity and specificity of ultrasound in predicting the outcome after ESWL for the same group of renal calculus is $95.8 \%$ and $50 \%$ respectively with a positive and negative predictive value of $97.8 \%$ and $33.33 \%$ respectively. These findings show that the two (USG and IVU) are comparable pre-ESWL diagnostic evaluating tools.

\section{Discussion}

Our study was designed to find out if ultrasound can replaced IVU as the alternative pre ESWL diagnostic tool in predicting the outcome after therapy.

Renal stones were usually described as more frequent in men [8]. Romero et al [9] in their review found that age at peak for kidney stones varies from country to country, incidence was similar in 3 countries, ranging from 40 to 49 years, while in other countries the peak increases with increasing age. In our study males constitute $66 \%$ and maximum distribution is in the age group of 21-40 years (54\%).

Lingeman et al documented that the incidence of calculi less than $10 \mathrm{~mm}$ is approximately $50-60 \%$ of all single renal stones [10] which is similar to our sample where we found out that $52 \%$ of all the solitary renal stones are $\leq 10 \mathrm{~mm}$ in sizes.

In kidneys with normal excretion, serum creatinine $<1.3$ $\mathrm{mg} / \mathrm{dl}$ and absence of any disease that can affect renal dimensions, USG is the technique of choice to measure dimensions.

Though IVU has always been the gold standard to show normal renal excretion before lithotripsy. In our study we have included two parameters as an indication of normal renal function. Firstly, in this study all cases with normal morphology of the kidney having normal renal size, parenchymal thickness and echogenicity were considered to have normal renal function therefore ruling out the possible sonographic features associated with non-functioning kidneys [5]. Secondly Only cases having ureteric jets as indication of excreting kidneys on ultrasound were included in this study in consensus with Budau M et al [11].

Budau $\mathrm{M}$ et al performed a comparative study between IVP (intravenous pyelography) and doppler ultrasound in assessing normal renal function. The ultrasound assessment of normal renal function consisted of the evaluation of ureteral flux (ureteral jets). The sensitivity in detecting ureteral flux (jets) in patients with pelvic stones and normal IVP was $100 \%$. They concluded that in cases of normal aspect of IVP the presence of ureteral flux assessed by ultrasound could substitute the IVP in the preoperative evaluation for ESWL treatment [11]. Doppler ultrasound could be the method of choice for pre ESWL renal function evaluation mainly for patients with known intolerance to contrast media.

Dalla-Palma L et al found the sensitivity and specificity of ultrasound in diagnosis of hydronephrosis to be $89.9 \%$ and $84.4 \%$ respectively on 125 patients [12]. Our study on 100 renal units yielded sensitivity and specificity of $96.7 \%$ and $94.2 \%$ respectively.

Efforts should be made to obtain true stone free status after ESWL. Clinical experience has shown that stone 
fragments $\leq 4 \mathrm{~mm}$ pass spontaneously in more than $80 \%$ of cases. Fragments with sizes between $1 \mathrm{~mm}$ and $4 \mathrm{~mm}$ remaining in the kidney three months after the treatment are usually considered insignificant residual fragments.

1(one) case in our study resulted in steinstrasse constituting $2 \%$ of all cases.

Coz et al 2000 found that percentage of stone free after 1 session of lithotripsy for upper, middle, lower calyx and renal pelvis are $78.5 \%, 81.9 \%, 74.6 \%$ and $78.6 \%$ respectively [13]. Our series shows comparative lower values after 1 session. However the stone free rate for our study after 2 sessions of lithotripsy for upper, middle, lower calyx and renal pelvic stones are 85.71 $\%, 91.67 \%, 50 \%$ and $94.74 \%$ respectively.

In our study a calculus of $10 \mathrm{~mm}$ located in the lower calyx resulted in unsuccessful outcome. A variety of factors may have been responsible for this result. Firstly the stone is located in the lower calyx which usually have a lower clearance rate and secondly the stone composition may have influenced the outcome. Lowest disintegration rates are noted for calcium oxalate monohydrate (COM) which is hard and in cystine which is elastic [14].

Gupta et al have found increasing stone free rates with smaller stones. Stone free rates varied from 38.7-72.1\% depending on the stone size. Stones of sizes $\leq$ to $10 \mathrm{~mm}$, $11-20 \mathrm{~mm}$ and $21-33 \mathrm{~mm}$ have stone free rate of $72.1 \%$, $51.3 \%$ and $38.7 \%$ respectively [15]. We also found in our series that smaller stones have higher stone free rates with lesser number of ESWL sessions.

Politis G and Griffith DP have shown that kidneys with small stones ( $\leq 15 \mathrm{~mm}$ in longest diameter) become stone free in $78 \%$ of the cases, whereas kidneys with large stones $(\geq 15 \mathrm{~mm}$ ) are stone free in only $66 \%$ of the cases [16].

Cheung $\mathrm{MC}$ et al in their study conclude that plain abdominal radiography plus ultrasound is highly sensitive for screening ureteral obstruction after primary in situ ESWL for ureteral calculi. It can save up to $74 \%$ of patients from potential risk of IVU [17]. The detection of cause of obstruction by IVU is only necessary when sonographic detection of hydronephrosis is present.
Dalla-Palma L et al studied 180 patients presenting to the emergency department with suspected ureteric colic over an 8 month period. They had a plain abdominal film (KUB) and ultrasound examination of the kidney, ureters and bladder following hydration. They concluded that if they had used KUB plus ultrasound alone as the first test, urography would have been unnecessary in approximately $60 \%$ [18].

Lewis Jones $\mathrm{HG}$ et al performed a prospective study on 328 patients who were referred for intravenous urography by also independently examining with ultrasound combined with plain radiography. The results were compared and in $81.4 \%$ of cases the two techniques yielded identical information. A scheme of routine urinary tract investigations using ultrasound and plain abdominal radiograph is proposed [19].

Diament MJ and Malekzadeh $\mathrm{M}$ retrospectively compared ultrasound examination with plain radiography of the abdomen (KUB) in the diagnosis of renal and ureteral calculi in 13 patients. Overall, ultrasound was more sensitive than KUB (84\% versus $54 \%$ ) in detecting calculi [20].

\section{Conclusion}

Ultrasound has a high sensitivity and low specificity for predicting the outcome of ESWL with comparable predictive values to IVU. Therefore ultrasound being a rapid, radiation free, easily available, portable and repeatable in multiple times during the treatment period can be an alternative diagnostic procedure to predict the outcome of ESWL for solitary renal stones. Favourable sonographic parameters for a successful outcome after lithotripsy on solitary renal stones include demonstration of ureteric jets, normal parenchymal thickness, normal cortical echogenicity, favourable stone location in the kidneys and nondilated or mild and moderate dilated collecting system having normal parenchymal thickness.

\section{Acknowledgement}

Dr Biona Kharrubon, Professor of Radiology, RIMS, IMPHAL, for her guidance.

Prof Jatishwor singh, Professor and head of Radiology for teaching, guidance and his constant encouragement and feedback.

All staffs of Radiodiagnosis and Urology Department, RIMS, Imphal. Manipur. 


\section{Funding: Nil \\ Conflict of interest: None. \\ Permission of IRB: Yes}

\section{References}

1. Platt JF, Rubin JM, Bowerman RA, Marn CS. The inability to detect kidney disease on the basis of echogenicity. AJR Am J Roentgenol. 1988 Aug;151(2):317-9.

2. Fowler CG. The kidneys and ureter. In: Rusell RCG, Williams NS and Bulstrode CJK. Bailey and Love's Short practice of Surgery. $24^{\text {th }}$ Edition London: A Hodder Arnold; 2004. 1313.

3. Cronan JJ. Urinary obstruction. In: Grainger RG, Allison D, Adam A and Dixon AK. Diagnostic Radiology. $4^{\text {th }}$ Edition China: Churchill Livingstone; 2001.1594.

4. Whitfield HN. Stone disease progress with lithotripsy. In: Hendry WF. Recent advances in urology / Andrology. No.5 New York: Churchill Livingstone; 1991. 13-36.

5. Behan M, Wixson D, Kazam E. Sonographic evaluation of the nonfunctioning kidney. J Clin Ultrasound. 1979 Dec;7(6):449-58.

6. Beland MD, Walle NL, Machan JT, Cronan JJ. Renal cortical thickness measured at ultrasound: is it better than renal length as an indicator of renal function in chronic kidney disease? AJR Am J Roentgenol. 2010 Aug;195(2):W146-9. doi: 10.2214/AJR.09.4104.

7. Siddappa JK, Singla S, Al Ameen M, Rakshith SC, Kumar N. Correlation of ultrasonographic parameters with serum creatinine in chronic kidney disease. J Clin Imaging Sci. 2013 Jun 30;3:28. doi: 10.4103/2156-7514.114809. eCollection 2013.

8. Trinchieri A. Epidemiology of urolithiasis: an update. Clin Cases Miner Bone Metab. 2008 May;5(2):101-6.

9. Romero V, Akpinar H, Assimos DG. Kidney stones: a global picture of prevalence, incidence, and associated risk factors. Rev Urol. 2010 Spring;12(2-3):e86-96.
10. Lingeman JE, Lifshitz DA and Evan PA. Surgical management of urinary lithiasis. In: Retik AB, Vaghan ED Jr and Wein AJ. Campbell's urology. $8^{\text {th }}$ edition Philadelphia: Saunders; 2002.3361-3451.

11. Budau M, Chira I, Ambert V, Pascu M, Radu M, Onu M, Pop T, Persu S, Popescu M, Braticevici B. Can we renounce performing the intravenous urography in the preoperative evaluation for ESWL treatment? Arch Ital Urol Androl. 2002 Jun;74(2):57-8.

12. Dalla-Palma L, Bazzocchi M, Pozzi-Mucelli RS, Stacul F, Rossi M, Agostini R. Ultrasonography in the diagnosis of hydronephrosis in patients with normal renal function. Urol Radiol. 1983;5(4):221-6.

13. Coz F, Orvieto M, Bustos M, Lyng R, Stein C, Hinrichs A, San Francisco I. Extracorporeal shockwave lithotripsy of 2000 urinary calculi with the modulith SL-20: success and failure according to size and location of stones. J Endourol. 2000 Apr;14(3):23946.

14. Dretler SP. Stone fragility--a new therapeutic distinction. J Urol. 1988 May;139(5):1124-7.

15. Gupta NP, Singh DV, Hemal AK, Mandal S. Infundibulopelvic anatomy and clearance of inferior caliceal calculi with shock wave lithotripsy. J Urol. 2000 Jan;163(1):24-7.

16. Politis G and Griffith DP. Stone free efficacy based upon stone size and location. Word J Urol 2000; 5: 255 258.

17. Cheung MC, Leung YL, Wong BBW, Chu SM, Lee F and Tam PC: Prospective study on ultrasonography plus plain radiography in predicting residual obstruction after extracorporeal shockwave lithotripsy for ureteral stones. Urology 2002; 59: 340-343.

18. Dalla-Palma L, Stacul F, Bazzocchi M, Pagnan L, Festini $G$ and Marega D. Ultrasonography and plain film versus intravenous urography in ureteric colic. Clin Radiol 1993; 47(5): 333-336.

19. Lewis-Jones HG, Lamb GH, Hughes PL. Can ultrasound replace the intravenous urogram in preliminary investigation of renal tract disease? A prospective study. Br J Radiol. 1989 Nov;62(743):97780. 
20. Diament MJ, Malekzadeh M. Ultrasound and the

Dec;109(6):980-3. diagnosis of renal and ureteral calculi. J Pediatr. 1986

\section{How to cite this article?}

Lynser D, Sinam SS, Singh LS. Comparison of ultrasonography and Intravenous urography in predicting the outcome of Extracorporeal Shockwave lithotripsy in nephrolithiasis. Int J Med Res Rev 2015;3(10):1174-1181. doi: 10.17511/ijmrr.2015.i10.212. 